\title{
Analysis of additive metals in fuel and emission aerosols of diesel vehicles with and without particle traps
}

\author{
Received: 24 February 2003 / Revised: 5 May 2003 / Accepted: 7 May 2003 / Published online: 19 July 2003
}

(C) Springer-Verlag 2003

\begin{abstract}
Fuel additives used in particle traps have to comply with environmental directives and should not support the formation of additional toxic substances. The emission of metal additives from diesel engines with downstream particle traps has been studied. Aspects of the optimisation of sampling procedure, sample preparation and analysis are described. Exemplary results in form of a mass balance calculation are presented. The results demonstrate the high retention rate of the studied filter system but also possible deposition of additive metals in the engine.
\end{abstract}

Keywords Particle trap - Vehicle emission - Diesel . Aerosol - Inductively coupled plasma mass spectrometry . ICP-MS · Inductively coupled plasma emission spectrometry $\cdot$ ICP-OES $\cdot$ Microwave digestion

\section{Introduction}

Diesel engines are essential for transportation and other heavy-duty industries but a major drawback is their pollutants. Even the latest diesel engines emit fine soot particles which can cause serious respiratory and cardiovascular health problems $[1,2,3,4,5]$. Several countries regulate particulate emissions and give directives for implementation and compliance. Some of these countries, e.g. Switzerland [6] and Germany [7], legislate special directives for heavy-duty vehicles in working areas like tunnel construction sites; based on the results of the VERT studies ("Verminderung der Emissionen von Real-Dieselmotoren im Tunnelbau", i.e. reduction of diesel engine emissions at tunnel construction sites) $[8,9]$.

Particle traps are suitable tools for minimising soot emissions. Different types are already available and many are appropriate for retrofitting of heavy-duty vehicles [10].

A. Ulrich (网) A. Wichser

EMPA Swiss Federal Laboratories

for Material Testing and Research,

Überlandstrasse 129, 8600 Dübendoif, Switzerland

e-mail: andrea.ulrich@empa.ch
Suitable filter systems must fulfil strict requirements. For example pore size must allow optimal retention of ultrafine particles with minimal clogging of the filter system. A technical challenge is the regeneration of clogged filters. Online regeneration demands a minimum temperature of $550^{\circ} \mathrm{C}$ and an oxygen content of $5 \%$, which cannot be attained without additional burners or catalytic combustion [9]. Transition or noble metals (e.g. $\mathrm{Ce}, \mathrm{Fe}, \mathrm{Cu}, \mathrm{Sr}$ or Pt) in the form of fuel additives or coatings can substantially lower the soot ignition temperature. At concentrations of $10-50 \mathrm{mg} / \mathrm{kg}$ the additives can be mixed with the fuel in the form of organometallic compounds or as oxides which give a colloidal suspension with the fuel. The additives should give a stable mixture with the diesel and must be well distributed within each micro-droplét during the combustion process.

Particle reduction must not provoke an increase of toxic components. Therefore the assessment of secondary emissions is an important criterion for the suitability of particle filters. An appropriate test should ensure suitability and toxic innocuousness of the particle trap. As one of the VERT partners, the EMPA studied both the trap-induced formation of hazardous organic compounds [11, 12] and the emission and penetration of additive metals which are presented here. The interest in online regeneration and potential supporting additives increased recently. A combination of cerium and iron was used in this study. Filter retention of ultra-fine particles and possible penetration of additive metals have been studied for a SiC wall-flow filter system in different driving situations: Emission rates were compared for the engine with and without a particle trap.

\section{Experimental}

Instrumentation

All fuel and filter samples were digested in an MLS 1200 Mega High-Petformance Microwave Digestion Unit (MSL GmbH) upgraded with a temperature control unit. The spectrometers used in the analysis of aqueous digestion solutions were a quadrupole ICP-MS ELAN 6000 (Perkin Elmer/Sciex) and a magnetic sector field ICP-MS ELEMENT II (Thermofinnigan), both operated under 
Table 1 Operating conditions for the ICP-MS and ICP-OES

\begin{tabular}{|c|c|c|c|c|}
\hline Parameter & $\begin{array}{l}\text { Perkin Elmer ELAN } \\
6000\end{array}$ & $\begin{array}{l}\text { Thermo-Finnigan } \\
\text { ELEMENT II }\end{array}$ & ARL 3580 B (Minitorch) & VARIAN VistaPro \\
\hline Power (W) & 1100 & 1100 & 750 & 1500 \\
\hline $\begin{array}{l}\text { Plasma gas flow } \\
(\mathrm{L} / \mathrm{min})\end{array}$ & 15 & 15 & 12 & 15 \\
\hline $\mathrm{RF}$ generator (MHz) & 40.86.(free-running) & 27,12 (solid state) & 27.12 (solid state) & 40.86 (free-running) \\
\hline Aux. gas flow (L/min) & 1.00 & 1.00 & 1.00 & 2.25 \\
\hline $\begin{array}{l}\text { Nebulizer gas flow } \\
\text { (L/min) }\end{array}$ & 0.92 & 0.89 & 0.70 & 0.70 \\
\hline Nebulizer & Crossflow & Meinhard K-type & Meinhard K-type & Meinhard K-type \\
\hline Spray chamber & Scott-type (Ryton) & Scott type & $\begin{array}{l}\text { Cooled conic quartz } \\
\text { chamber }\left(-1^{\circ} \mathrm{C}\right)\end{array}$ & Cooled quartz chamber \\
\hline Resolution & about $0.75 \mathrm{amu}$ & $\begin{array}{l}\text { Low } \approx 300 \\
\text { Medium } \approx 4000 \\
\text { High } \approx 10,000\end{array}$ & $\begin{array}{l}\text { about } 9-10 \mathrm{pm} \\
\text { (at } 267.7 \mathrm{~nm} \text { ) }\end{array}$ & $\begin{array}{l}\text { about } 10 \mathrm{pm} \\
\text { (at } 267.7 \mathrm{~nm} \text { ) }\end{array}$ \\
\hline Dynamic range & $10^{9}$ (Dual-mode ETP) & $10^{9}$ (Dual-mode ETP) & $10^{6}$ & $\begin{array}{l}10^{6}(\mathrm{CCD}, \\
70,000 \text { pixels })\end{array}$ \\
\hline Wavelength range & & & $167-785 \mathrm{~nm}$ & $167-785 \mathrm{~nm}$ \\
\hline
\end{tabular}

standard plasma conditions (Table 1). Direct determinations of the diesel samples were performed with a radial ARL 35.80 B ICP Analyser (ARL) or a radial VistaPro ICP-OES (Varian). Chlorine arid sulphur were determined directly in undiluted samples using a Philips PW-1400 wavelength-dispersive $\mathrm{X}$-ray fluorescence spectrometer (WD-XRF) with typical detection limits of $1-2 \mu \mathrm{g} / \mathrm{g}$.

\section{Reagents and chemicals}

In aqueous solutions only ultra-pure quality acids (Merck) and highpurity water $(18.2 \mathrm{M} \Omega \mathrm{cm})$, prepared by a Milli-Q Gradient A10 System (Millipore), were used for sample and standard prepara'tion. Standards were prepared from single- and multi-element standards to ICP quality (Merck and Alfa Aesar). Cleaning and filter digestions were also only perfonned using acids of ultra-pure quality (Merck) and high-purity water.

Diesel samples were diluted using xylene as a mixture of isomers, "puriss. p.a." (Fluka). Calibration standards were prepared from Conostan organometallic single- and multi-element standards in Natural Basis Oil 75 (Conostan). For diesel digestions suprapure quality acid (Merck) was used.

\section{Direct determination of metals in diesel}

A rapid method was needed for monitoring accuracy of additive dosing as well as miscibility and stability of the additive-fuel mixtures. Inductively coupled plasma optical emission spectrometry (ICP-OES) has proved to be a reliable technique for direct element determinations in a variety of organic samples [13]. Oil or fuel samples must usually be diluted using organic solvent to decrease viscosity and to guarantee a reliable quantification. Various organic solvents like MIBK $[14,15,16]$, toluene [17], xylene [18, $19,20,21]$ or kerosene $[22,23,24,25]$ were investigated for different applications. Xylene and kerosene showed good plasma stability under similar plasma conditions as for aqueous solutions. In newer publications kerosene was often preferred due to lower costs, toxicity, volatility and less carbon build-up. However a great advantage of xylene appears to be an increase in stability of sample solutions and standards. Moreover, numerous organic petrochemical solutions do not dissolve completely even at high kerosenesample ratios, and those that do are unstable. A main goal was that the final procedure was appropriate for element determination in diesel and lubricants, since both sample types have to be analysed within VERT projects. Prior tests of solubility with different organic solvents showed that xylene has better solubility properties
Table 2 . BEC for directly determined diesel samples (diluted 1:5 with xylene) calculated for undiluted samples

\begin{tabular}{llrr}
\hline Element & $\begin{array}{l}\text { Wavelength } \\
\text { in nm }\end{array}$ & $\begin{array}{c}\text { ARL 3580 B } \\
\text { Minitorch } \\
\text { radial }\end{array}$ & $\begin{array}{c}\text { VARIAN } \\
\text { Vista Pro } \\
\text { radial }\end{array}$ \\
\hline $\mathrm{Ag}$ & 328.068 & 2.45 & 2.15 \\
$\mathrm{Al}$ & 237.312 & 19.89 & 14.98 \\
$\mathrm{~B}$ & 249.678 & 6.28 & 3.05 \\
$\mathrm{Ba}$ & 455.403 & 1.08 & 1.24 \\
$\mathrm{Ca}$ & 317.933 & 4.31 & 9.94 \\
$\mathrm{Cd}$ & 226.502 & 0.88 & 1.01 \\
$\mathrm{Cr}$ & 267.716 & 2.22 & 1.61 \\
$\mathrm{Cu}$ & 324.754 & 2.32 & 2.11 \\
$\mathrm{Fe}$ & 259.940 & 2.27 & 1.73 \\
$\mathrm{Mg}$ & 280.270 & 0.19 & 0.24 \\
$\mathrm{Mn}$ & 257.610 & 0.57 & 0.28 \\
$\mathrm{Mo}$ & 202.032 & 1.91 & 2.10 \\
$\mathrm{Ni}$ & 221.648 & 1.60 & 7.41 \\
$\mathrm{Ni}$ & 231.604 & 13.22 & 12.48 \\
$\mathrm{P}$ & 178.222 & 5.09 & 11.77 \\
$\mathrm{~Pb}$ & 220.353 & 12.20 & 15.77 \\
$\mathrm{Si}$ & 251.611 & 8.41 & 5.29 \\
$\mathrm{Ti}$ & 337.280 & 2.02 & 2.29 \\
$\mathrm{~V}$ & 311.070 & 2.50 & 3.55 \\
$\mathrm{Zn}$ & 213.857 & 0.72 & 1.13 \\
\hline
\end{tabular}

for both sample types [26]. A further advantage of xylene is the relatively low background level combined with a good signal-tonoise ratio, which resulted in good background equivalent concentrations (BEC): Therefore xylene was chosen to optimise direct determination using ICP-OES and resulted in the followimg procedure: all organic samples directly determined using ICP-OES were diluted 1:5 with xylene; a mixture of xylene isomers was used, puriss. p.a. (Fluka); calibration standards. were prepared from Conostan organometallic single- and multi-element standards in concentrations of $2,10,50$ and if required $250 \mathrm{mg} / \mathrm{kg}$ in Conostan Natural Basis Oil 75; and the same basis oil was used as blank:

For calibration all standards and the blank were diluted 1:5 with xylene. In Table 2 selected BEC values, calculated for undiluted samples, are listed. Usually organic solutions show higher 
background levels than aqueous solutions. Therefore the use of BEC levels for organic solutions is advantageous over detection limits because BECs are calculated without backgtound-corrected values. BEC level is defined as follows:

$B E C=1 /\left[\left(I_{\text {Standard }}-I_{\text {Blank }}\right) / c_{\text {Standard }}\right] * I_{\text {Blank }}$

where $\mathrm{I}_{\text {Standard }}=$ intensity standard (background not corrected), $\mathrm{I}_{\text {Blank }}=$ intensity blank (background not corrected). and $\mathrm{c}_{\text {Standard }}=$ concentration standard.

In this paper only the results of iron (direct determination) and cerium (determination after digestion) will be discussed, but the BEC list also includes other elements which are characteristic of diesel or lubricants (e.g. abrasion) and were studied within the project.

\section{Decomposition of diesel}

For some elements like cerium the direct determination method was not applicable as no organic standards were available. Therefore digestion was optimised using an MLS 1200 Mega High-Performance Microwave Digestion Unit (MSL GmbH). Wet-acid digestions of organic samples present safety hazards [27, 28, 29, 30]. Therefore a slow procedure was developed where the diesel samples were digested with nitric acid and peroxide. About $100-200 \mathrm{mg}$ of sample was weighed into quartz vessels and $3 \mathrm{ml}$ of nitric acid $\left(\mathrm{HNO}_{3,}\right.$, Merck ultra-pure $\left.60 \%\right)$ was added. The quartz vessels were covered and slowly heated on a Schott Ceran hotplate to ensure a smooth pre-reaction. When the reaction started the colour changed from yellow to brown and the formation of $\mathrm{NO}_{\mathrm{x}}$. was observed. After $12 \mathrm{~h}$ reaction time and cooling, $1 \mathrm{ml}$ hydrogen peroxide $\left(\mathrm{H}_{2} \mathrm{O}_{2}\right.$, Merck supra-pure $\left.30 \%\right)$ was added to the solutions. The digestion vessels were placed into medium-pressure decomposition vessels, which were filled with $5 \mathrm{mll}$ ultra-pure water and $1 \mathrm{ml}$ $\mathrm{H}_{2} \mathrm{O}_{2}$ (Merck supra-pure 30\%), and microwave digestion was performed. Finally the solutions were diluted to an end volume of $10 \mathrm{ml}$. The complete digestion programme is listed in Table 3 . Additive elements were determined by ICP-OES and ICP-MS using aqueous calibration solutions.

\section{Filter sample preparation}

The emission aerosols were sampled on. Nuclepore Track-Etch Membranes IPR-200 (Corning) using a Dekati 12-stage Electrical Low Pressure Impactor (ELPI), Model 95 2E Sn 24/50 (size range $30 \mathrm{~nm}-10 \mu \mathrm{m})$ and a downstream quartz fibre back-up filter.

The ELPI samples showed very low aerosol masses and the concentrations of the additive elements were at the ultra-trace level. The required low detection limits (DL) were only achievable

\section{Table 3 Digestion programme for diesel samples}

\begin{tabular}{|c|c|c|c|c|}
\hline \multicolumn{5}{|c|}{ Prè-digestion programme } \\
\hline \multicolumn{2}{|c|}{ Time } & \\
\hline $3 \min$ & . & \multicolumn{3}{|c|}{$\begin{array}{l}\text { Ceran hotplate level } \\
1\end{array}$} \\
\hline \multicolumn{2}{|l|}{$7 \min$} & \multicolumn{3}{|c|}{2} \\
\hline \multicolumn{2}{|l|}{$5 \mathrm{~min}$} & \multicolumn{3}{|l|}{$\begin{array}{l}2 \\
0\end{array}$} \\
\hline \multirow{2}{*}{\multicolumn{4}{|c|}{$\begin{array}{l}10 \min \\
\text { Cooling down, } 12 \mathrm{~h} \text { reaction time before adding } \mathrm{H}_{2} \mathrm{O}_{2}\end{array}$}} & \\
\hline \multicolumn{3}{|c|}{ Cooling down, $12 \mathrm{~h}$ reaction time before adding $\mathrm{H}_{2} \mathrm{O}_{2}$} & & \\
\hline \multicolumn{5}{|c|}{ Microwave digestion programme } \\
\hline Step & $\begin{array}{l}\text { Time } \\
\text { (min) }\end{array}$ & $\begin{array}{l}\text { Power } \\
\text { (W) }\end{array}$ & $\begin{array}{l}\text { Temperature } \\
\text { outside }\left({ }^{\circ} \mathrm{C}\right)\end{array}$ & $\begin{array}{l}\text { Temperature } \\
\text { inside }\left({ }^{\circ} \mathrm{C}\right)\end{array}$ \\
\hline 1 & 6 & 1000 & 100 & 90 \\
\hline 2 & 6 . & 1000 & 150 & 130 \\
\hline 3 & 9 & 1000 & 210 & 130 \\
\hline 4 & 12 & 1000 & 215 & 130 \\
\hline 5 & 30 & Cooling & & \\
\hline
\end{tabular}

by consequent optimisation of the whole sample preparation procedure. To minimise the contamination risk only fresh acids of ultra-pure quality were used. First results showed that only control of all vessels after cleaning digestion led to appropriate DLs [31]. The quartz vessels were reserved for these applications only. The following procedure was optimised to achieve the best detection limits:

(1) Cleaning digestion for the vessels using ultra-pure chemicals and filled to an end volume of $10 \mathrm{ml}$.

(2) Determination of the vessel background (cleaning solutions of (1)) by ICP-MS

(3) Selection of suitable vessels based on the results of (2).

(4) Vessels with inappropriate background levels have to be cleaned a second time ; steps repeated from (1).

(5) Digestion of the weighed filters (field blanks and samples) using ultra-pure chemicals (acid mixture depends on analyte) and filled to an end volume of $10 \mathrm{ml}$.

(6) Digestion of a minimum of five reagent blanks together with (5) to determine the detection limits of the sample preparation procedure using the same acids as in (5).

(7) Determination using ICP-MS (inductively coupled plasma mass spectrometry - quadrupole or high-resolution (HR)ICP-MS is dependent on the analyte).

The acid mixture for the digestion depends on the elements of interest and the filter type. As an example the decomposition of ELPI filters for the determination of iron and cerium is described here. The absolute aerosol masses on the 12 impactor stages were directly monitored during sampling. This was an advantage because determination by difference weighing (loaded filter-unloaded filter) was not always possible due to condensation on the filter surface.

In this study the whole filter was weighed and placed into a cleaned and background controlled decomposition vessel. A 3-ml aliquot of $\mathrm{HNO}_{3}$ (Merck ultra-pure 60\%) and $1 \mathrm{ml} \mathrm{H}_{2} \mathrm{O}_{2}$ (Merck ultra-pure $30 \%$ ) were added. The vessels were closed and placed into the outer decomposition vessels, which were filled with $5 \mathrm{ml}$ ultrapure water and $1 \mathrm{ml} \mathrm{H}_{2} \mathrm{O}_{2}$ (Merck ultra-pure 30\%). The microwave decomposition programme is described in Table 4. Finally the solutions were diluted to $10 \mathrm{ml}$ end volume with, ultra-pure water.

For the determination, aqueous standards were prepared using single- or multi-element standards of ICP quality (Merck and Alfa Aesar), ultra-pure quality acids (Merck) and high-purity water, prepared using a Milli-Q Gradient A10 System (Millipore).

The selection of an interial standard for the determination of emission aerosols can be challenging because generally recoinmended elements, such as rhodium, are not always applicable. Further tests, which have yet to be published, showed that emission aerosols of engines equipped with oxidation catalysts, and particle traps have sometimes a significantly higher concentration of metals like rhodium, rhenium or yttrium. In such cases, appropriate selection is only possible on the basis of prior semi-quantitative analysis. Elements like indium, molybdenum or probably gallium seemed to be appropriate candidates, but the applicability of an intemal standard must be checked in every individual case. In the present study the use of rhodium was possible because no oxidation catalyst was used in combination with the studied particle trap. Cerium and iron were determined using HR ICP-MS.

Back-up filters and filter materials for integral sampling of diesel exhaust emissions were digested with $\mathrm{HNO}_{3}$ (Merck ultra-

Table 4 Microwave digestion programme for ELPI filter samples

\begin{tabular}{lclll}
\hline Step & $\begin{array}{l}\text { Time } \\
(\mathrm{min})\end{array}$ & $\begin{array}{l}\text { Power } \\
(\mathrm{W})\end{array}$ & $\begin{array}{l}\text { Temperature } \\
\text { outside }\left({ }^{\circ} \mathrm{C}\right)\end{array}$ & $\begin{array}{l}\text { Temperature } \\
\text { inside }\left({ }^{\circ} \mathrm{C}\right)\end{array}$ \\
\hline 1 & 6 & 1000 & 100 & 80 \\
2 & 6 & 1000 & 150 & 130 \\
3 & 10 & $1000 \quad$. & 180 & 130 \\
4 & 12 & 600 & 180 & 130 \\
5 & 30 & Cooling/venting & \\
\hline
\end{tabular}


Table 5 Background contamination of different filter materials in $\mu \mathrm{g} / \mathrm{m}^{2}$

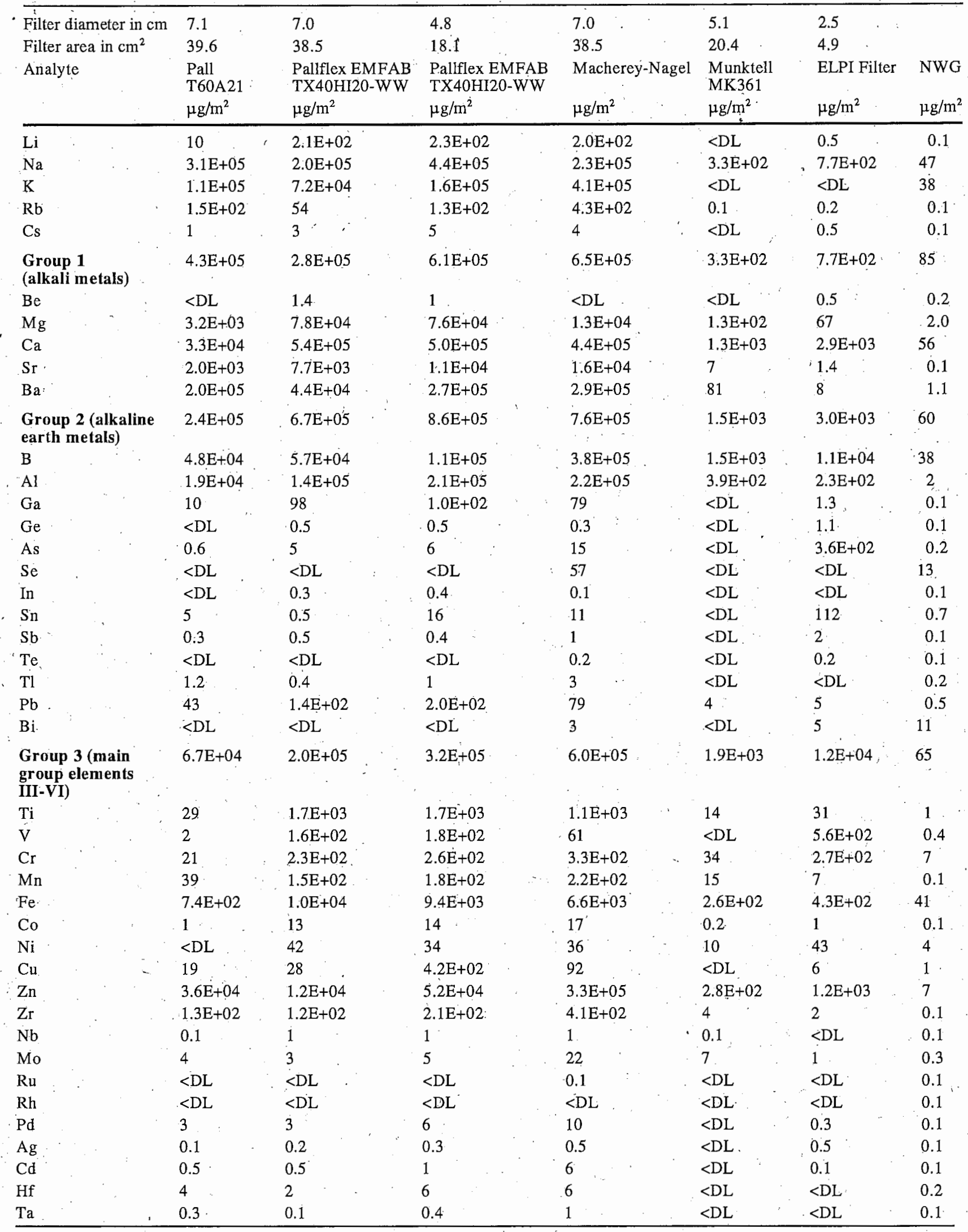


Table 5 (continued)

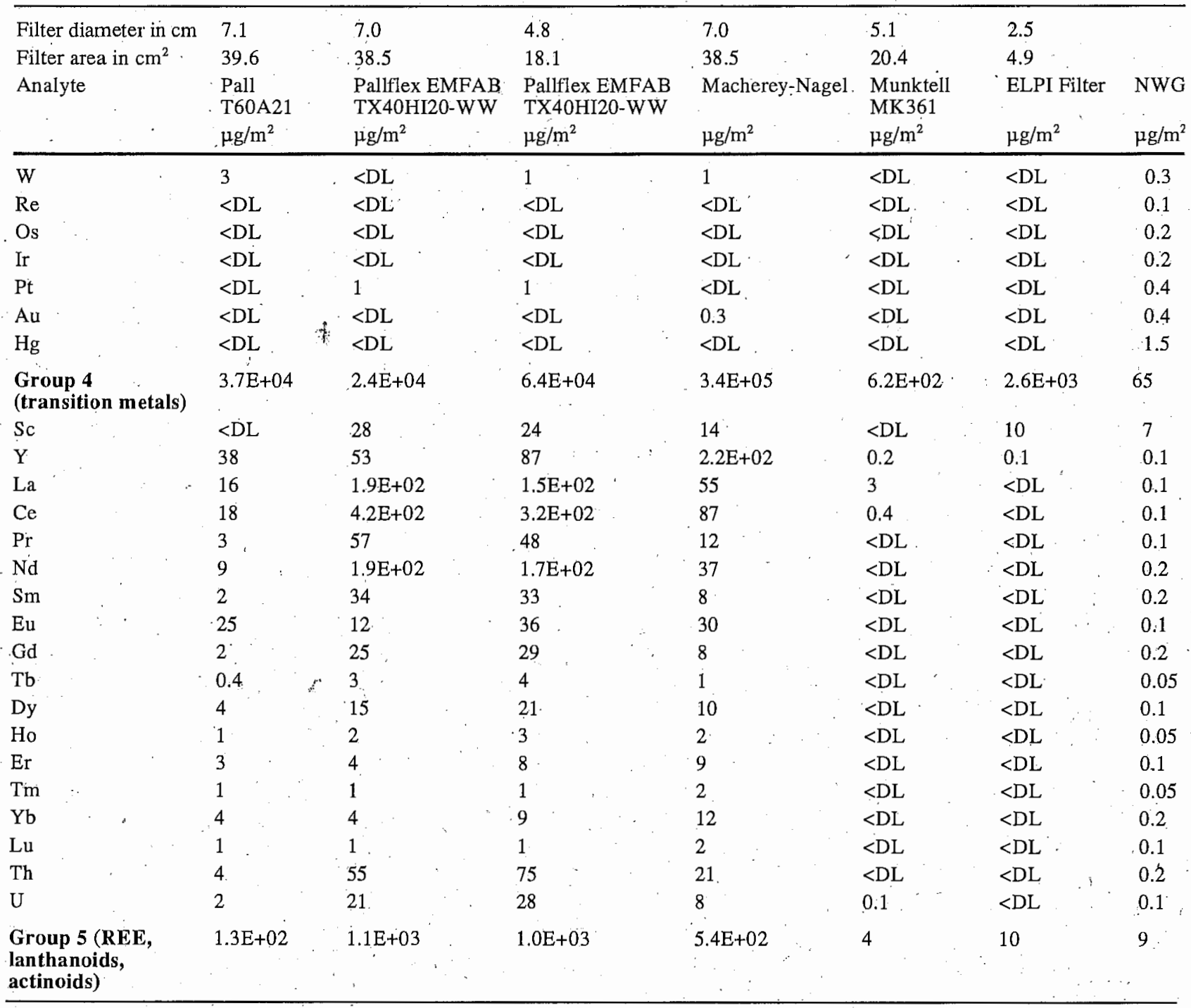

pure $60 \%$ ) and $\mathrm{H}_{2} \mathrm{O}_{2}$ (Merck ultra-pure $30 \%$ ) using microwave digestion. The samples were prepared without internal standard. The Totalquant program of the ELAN 6000 was used to determine the background levels of the filters:

\section{Results and discussion}

Filter background levels

Metal determination in emission aerosols is limited more by sampling procedure than by the detection limits of analytical methods. The main reason is a high contamination risk during sampling. A consequent optimisation of the complete chain including sampling procedure, sample preparation and analysis is needed to achieve reliable results [3.1, 32]. The determination of additive metals in extremely low concentrations requires a suitable sampling procedure. Contamination risk and memory effects are not negligible especially for omnipresent metals. A pre-condition for low detection limits is a careful selection of filter material with low background. Therefore several filter types planned for different applications within this research project were controlled for their background level. Three samples of each filter type were microwave digested and determined using the semi-quantitative program of the ICP-MS. Table 5 shows the average results of all filter materials studied, which are listed in Table 6: The three filter samples varied mainly between 5 and 30\% depending on filter type, element and concentration. To give a quick overview the results, calculated in concentrations based on filter areas, were summarised in five groups (Fig. 1):

(1) Sum of alkali metals

(2) Sum of alkaline earth metals

(3) Sum of main group elements (III to VI)

(4) Sum of tranisition metals

(5) Sum of rare earth elements, REE 
Table 6 Filter materials and properties

\begin{tabular}{|c|c|c|c|c|c|}
\hline Filter type & Diameter & Material & Properties & Application & Package \\
\hline $\begin{array}{l}\text { Pall Gelman Sciences Pallflex } \\
\text { membrane filter, Type EMFAB } \\
\text { TX40HI20WW-47 mm }\end{array}$ & $47 \mathrm{~mm}$ & $\begin{array}{l}\text { Boron-silicate } \\
\text { glass micro-fibres } \\
\text { reinforced with } \\
\text { woven glass cloth, } \\
\text { PTFE bonded }\end{array}$ & $\begin{array}{l}\text { 1. Withstands folding } \\
\text { 2. Flushed with DI } \\
\text { water to remove water- } \\
\text { soluble residue } \\
\text { 3. Low air resistance } \\
\text { for critical aerosol } \\
\text { sampling }\end{array}$ & $\begin{array}{l}\text { High temperature or } \\
\text { hot gas air monitoring }\end{array}$ & Plastic box \\
\hline $\begin{array}{l}\text { Pall Gelman Sciences.Pallflex } \\
\text { membrane filter, Type EMFAB } \\
\text { TX40HI20WW-70 mm }\end{array}$ & $70 \mathrm{~mm}$ & $\begin{array}{l}\text { Boron-silicate } \\
\text { glass micro-fibres } \\
\text { reinforced with } \\
\text { woven glass cloth, } \\
\text { PTFE bonded }\end{array}$ & $\begin{array}{l}\text { 1. Withstands folding } \\
\text { 2. Flushed with DI } \\
\text { water to remove water- } \\
\text { soluble residue } \\
\text { 3. Low air resistance } \\
\text { for critical aerosol } \\
\text { sampling }\end{array}$ & $\begin{array}{l}\text { High tem } \\
\text { hot gas a }\end{array}$ & $\begin{array}{l}\text { Paperboard } \\
\text { box filters in } \\
\text { plastic bag }\end{array}$ \\
\hline $\begin{array}{l}\text { Pall Gelman Sciences Pallflex } \\
\text { membrane filter, Type Fiberfilm } \\
\text { T60A21-47 mm }\end{array}$ & $47 \mathrm{~mm}$ & $\begin{array}{l}\text { Heat resistant } \\
\text { boron-silicate glass } \\
\text { fibre coated with } \\
\text { fluorocarbon (TFE) }\end{array}$ & $\begin{array}{l}\text { 1. Heat-treated (HAT) } \\
\text { version available for } \\
\text { reduction of trace } \\
\text { organics }\end{array}$ & $\begin{array}{l}\text { High temperature or } \\
\text { hot gas air monitoring; } \\
\text { air sampling applica- } \\
\text { tions with moisture } \\
\text { variations in air or } \\
\text { gases }\end{array}$ & $\begin{array}{l}\text { Paperboard } \\
\text { box filters in } \\
\text { plastic bag }\end{array}$ \\
\hline $\begin{array}{l}\text { Munktell quartz microfibre filter, } \\
\text { Type MK } 360 / T 293\end{array}$ & $50 \mathrm{~mm}$ & $\begin{array}{l}\text { Pure quartz micro- } \\
\text { fibre without glass } \\
\text { fibre and binder }\end{array}$ & 3 & $\begin{array}{l}\text { Emission control up } \\
\text { to } 900-950^{\circ} \mathrm{C}\end{array}$ & Paperboard \\
\hline $\begin{array}{l}\text { Macherey-Nagel, Type glass } \\
\text { fibre filter } \mathrm{MN} 85 / 90 \mathrm{BF}\end{array}$ & $70 \mathrm{~mm}$ & $\begin{array}{l}\text { Glass fibre filter } \\
\text { without organic } \\
\text { binder }\end{array}$ & $\therefore$ & Filter for coulometry & \\
\hline $\begin{array}{l}\text { Corning, Nuclepore Track-Etch } \\
\text { Membrane IPR-200 }\end{array}$ & $25 \check{\mathrm{mm}}$ & Polycarbonate & - & $\begin{array}{l}\text { Films for ELPI } \\
\text { Electrical Low } \\
\text { Pressure Impactor, } \\
\text { fuel testing }\end{array}$ & Plastic box \\
\hline
\end{tabular}

Fig. 1 Background levels of different filter materials

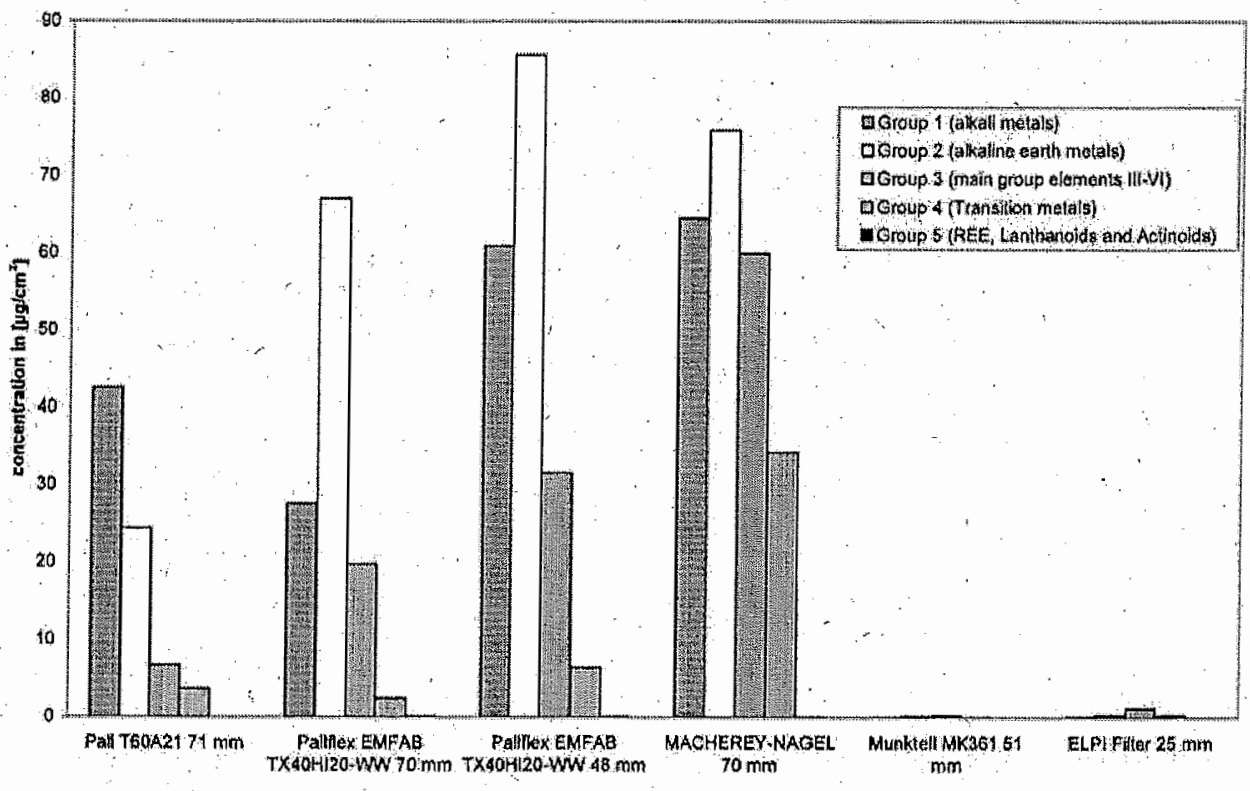

ELPI and Munktell filters showed the lowest concentrations and were preferred by the authors. Macherey-Nagel and Pallflex filter types showed higher background levels. The highest levels in group (1) were observed for sodium and potassium. Calcium, barium and magnesium con- tributed mainly to group (2). Aluminium and boron were dominant in group (3) and zinc followed by iron in group (4). Group (5) was for all filters below $0.1 \mu \mathrm{g} / \mathrm{m}^{2}$. The background levels of potential additive or coating metals (Ce, $\mathrm{Fe}, \mathrm{Sr}, \mathrm{Pt}$, etc.), typical metals originating from oxi- 
dation catalysts ( $\mathrm{Re}, \mathrm{Rh}, \mathrm{Pt}$, etc.) and candidates for internal standardisation (e.g. Rh, In, Y, Ga, etc.) are especially relevant to the VERT research projects. However the information about background levels might also be useful for other authors because the filter types are widespread and commonly used products:

Results for a $\mathrm{SiC}$ wall-flow filter system driven with cerium and iron additive-containing diesel

The presented results were part of a study within the VERT research programme. Illustrative results for a new $\mathrm{SiC}$ wall-flow filter system driven with cerium and iron additive-containing diesel arereported here. All tests were performed on an engine test stand with a LIEBHERR $914 \mathrm{~T}$ diesel engine (6.11 litre, $105 \mathrm{~kW}$ at 2,000 rpm, turbocharger without charge-air cooling.) by the Department of Auto1notive Engineering in Biel (Switzerland). Besides the investigation on metal penetration several other aspects like the formation of organic emissions were studied. These results will be presented elsewhere. The experimental set-up and the determined parameters are outlined in Fig. 2.

The ISO $8178 / 4 \mathrm{C} 1$ cycle with eight operating points for construction site engines was the basis for all emission

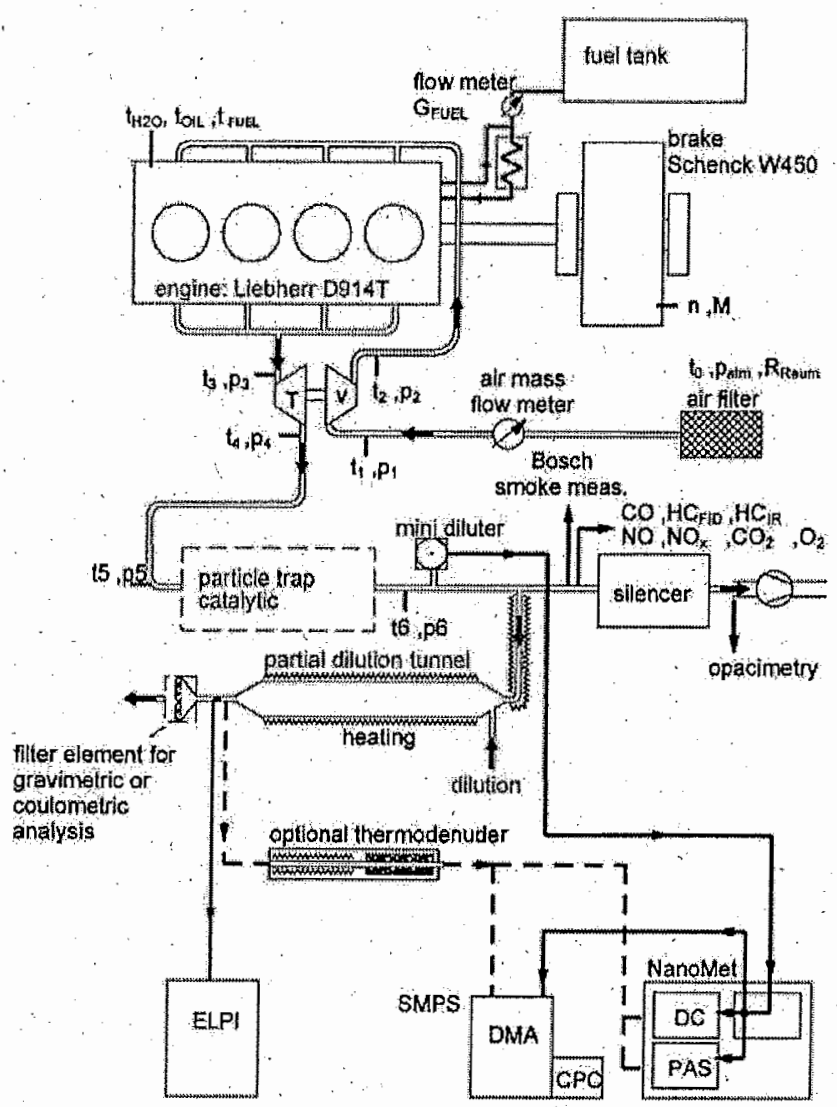

Fig. 2 Scheme of the experimental set-up for suitability testing of particle trap systems and the determination of secondary emissions

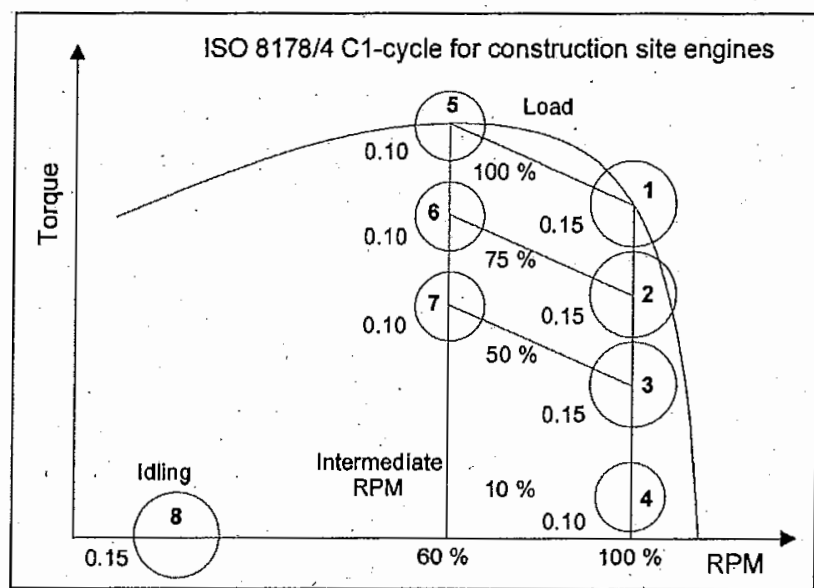

Fig. 3 ISO 8178/4 C1 cycle for construction site engines

measurements (Fig. 3). The cycle simulates different engine operating situations as well as the accumulation and regeneration phases of the particle trap. The cycle was driven in the prescribed sequence beginning with four load-states at a maximum of $2,000 \mathrm{rpm}$ followed by three load-states at an intermediate $\mathrm{rpm}(60 \%$ of the rated $\mathrm{rpm})$ and finally an idling phase. The dwell time of each load/ rpm point was $10-15 \mathrm{~min}$. The total cycle time was aggregated to $100 \mathrm{~min}$. The described cycle was driven twice, thus the total sampling time was $200 \mathrm{~min}$. The following five test conditions were used:

(1) RO: engine driven with reference diesel without fuel additives and without particle trap

(2) $\mathrm{CO}$ : engine driven with cerium and iron additive-containing diesel without particle trap

(3) CF: engine driven with cerium and iron additive-containing diesel with particle trap

(4) HCO: engine driven with cerium, iron and chlorine additive-containing diesel without particle trap

(5) HCF: engine driven with cerium, iron and chlorine additive-containing diesel with particle trap

The engine was operated with a standard diesel fuel as per EN SN 590 (poly,aromatics: $3.5 \mathrm{mg} / \mathrm{kg}$, density: 0.832 , cetane number: 56.6). Particle traps require diesel with low sulphur content: The reference diesel was delivered in a 200-1 barrel and the engine was directly fed from the barrel. The sulphur content was $94 \mathrm{mg} / \mathrm{kg}$. DEA DES/6069 (TBN: $0.55 \mathrm{mg} \mathrm{KOH} / \mathrm{g}$ ) with a sulphur content of $5 \mathrm{mg} / \mathrm{kg}$ was used as lubricant. Cerium and iron additives were added to support the particle trap regeneration. The supplementary chlorine additive serves to improve verification of polychlorinated dibenzodioxins/furans (PCDD/F) and increase sensitivity. The additives were dosed in the amounts $12 \mathrm{mg} / \mathrm{kg}$ cerium, $5 \mathrm{mg} / \mathrm{kg}$ iron and $12 \mathrm{mg} / \mathrm{kg}$ chlorine:

The correct dosing of the additives was controlled by the determination procedures described above. Therefore three diesel samples were taken during the motor test phase. The first diesel sample was taken directly from the 
freshly opened barrel before the tests got started. After RO was finished, the metal additives were well mixed with the fuel in the barrel and a sample of the additivecontaining diesel was taken. When the tests $\mathrm{CO}$ and $\mathrm{CF}$ were finished a chlorine additive was added to support the formation of organic secondary emissions. After chlorine was added, a third diesel sample was taken before the tests $\mathrm{HCO}$ and $\mathrm{HCF}$ were performed.

Iron was determined directly in a 1:5 xylene dilution using ICP-OES, cerium was quantified after digestion by ICP-OES and chlorine and sulphur were analysed using WD-XRF.

Emissions for the five test conditions described above were sampled using the commercial particle sampler Dekati ELPI. Further descriptions of the ELPI were given by other authors $[33,34]$ as well as restrictions for the ELPI in diesel particulate measurements [35]. Aerósol samples were taken from the partial dilution tunnel on pure Nuclepore Track-Etch Membranes IPR-200 (Corning). The sampling followed the steps described below:

(1) The ELPI was equipped with filters before installation at the motor test stand.

(2) Installation of the ELPI according to Fig. 1, but with absolute filter at inlet.

(3) Start of the ELPI and adjustment of the flow (100 mbar absolute pressure at outlet).

(4) Adjustment of the partial dilution tunnel (VT) (total flow $=2.09 \mathrm{~g} / \mathrm{s}$, dilution air $=2.0 \mathrm{~g} / \mathrm{s}$ ); sample flow is defined as total flow VT+flow ELPI (101/min) $\mathrm{mi}-$ nus dilution air.

(5) After the engine was conditioned, sampling was started by switching from the absolute filter to VT:

(6) The flow per stage was measured at each operating point of the ISO 8178/4 C1 cycle using the corona charger to determine number of particles and mass deposition for size distribution.

(7) Sampling duration: 200 min non-stop.

(8) Stop of sampling by change from VT to absolute filter.

(9) Stop of the flows and instrument.

(10) Change of the filters:

- Step by step the loaded filters were removed from each impactor stage using clean tweezers and put into unused petri dishes.

- After careful cleaning of the stages fresh filters were inserted using clean tweezers.

- The filter change was not performed in the motor house but in a room with separate ventilation system.

The background level was determined using diesel without additive and without particle trap (RO). To assess the total additive amount that finally reached the particle trap the sample $\mathrm{CO}$ was taken using additive-containing diesel without particle trap. The efficiency of the trap could be calculated by comparison of the $\mathrm{CO}$ and $\mathrm{CF}$ test conditions. The tests were repeated with an additional chlorine additive ( $\mathrm{HCF}$ and $\mathrm{HCO}$ ) to support the determination of organic compounds.
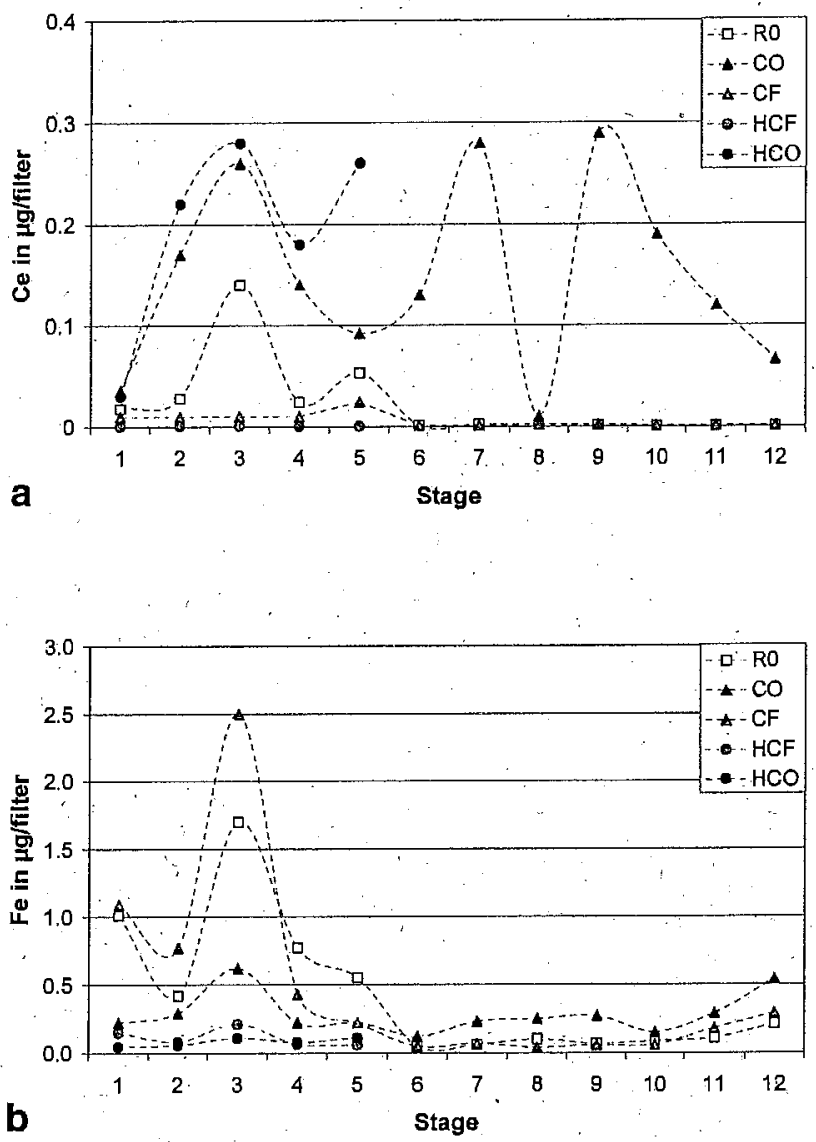

Fig. 4a,b Size-specific cerium and iron concentrations found on the 12 impactor stages in $\mu \mathrm{g}$ per filter

Table 7 Mass balance for cerium additive calculation based on total mass per cycle

\begin{tabular}{lcc}
\hline Data based on total mass per cycle & Cerium & $\%$ \\
\hline Dosed additive quantity & $473 \mathrm{mg}$ & 100 \\
Total mass exhaust gas without & $15.4 \mathrm{mg}$ & 3.3 \\
particle trap (calculation based on & & \\
measured total mass ELPI) & $0.3 \mathrm{mg}$ & 0.1 \\
$\begin{array}{l}\text { Total mass exhaust gas with trap } \\
\text { (calculation based on measured }\end{array}$ & $\therefore$ & \\
total mass ELPI) & $457 \mathrm{mg}$ & 96.7 \\
Calculated deposition in engine & $15.1 \mathrm{mg}$ & 3.2 \\
Calculated deposition in the & & \\
particle trap & $0.3 \mathrm{mg}$ & 0.1 \\
Calculated emission into ambient air & $473 \mathrm{mg}$ & 1.00 \\
Total & $96.7 \%$ & \\
Calculated filtration rate engine & $98.2 \%$ & \\
Calculated filtration rate particle trap & $99.9 \%$ & \\
Calculated total filtration rate system & $9.96 \mu \mathrm{g} / \mathrm{kWh}$ & \\
Emissions factor & $0.2 \mu \mathrm{g} / \mathrm{mm}^{3}$ & \\
\hline
\end{tabular}

The size distribution of particulate diesel exhaust emis sions has been studied in other papers [36, 37, 38]. It was also observed that cerium additive-containing diesel emis- 
Table 8 Mass balance for iron additive calculation based on total mass per cycle

\begin{tabular}{llr}
\hline Data based on total mass per cycle & Iron & $\%$ \\
\hline Dosed additive quantity & $202 \mathrm{mg}$ & 100 \\
Total mass exhaust gas without particle & $25.6 \mathrm{mg}$ & 12.7 \\
trap (calculation based on measured total & & \\
mass ELPI) & & \\
Total mass exhaust gas with trap & $43.2 \mathrm{mg}$ & 21.4 \\
(calculation based on measured total & & \\
mass ELPI) & & \\
Calculated deposition in engine & $176 \mathrm{mg}$ & 87.1 \\
Calculated deposition in the particle trap & $17.6 \mathrm{mg}$ & 3.7 \\
Calculated emission into ambient air & $43.2 \mathrm{mg}$ & 9.1 \\
Total & $236.8 \mathrm{mg}$ & 100 \\
Calculated filtration rate engine & $87.3 \%$ & \\
Calculated filtration rate particle trap & $-145 \%$ & \\
Calculated total filtration rate system & $78.6 \%$ & \\
Emissions factor & $632 \mu \mathrm{g} / \mathrm{kWh}$ & \\
& $39 \mu \mathrm{g} / \mathrm{nm}^{3}$ & \\
\hline
\end{tabular}

sions show a bimodal distribution and that different $\mathrm{Ce}$ concentrations change the size distribution to smaller size classes [32, 39, 40]. However little is known about metal. content in the different size fractions and the behaviour of additives like iron. Figures $4 a$ and $b$ present the size-classified cerium and iron content for the five different test conditions described above as mass per impactor stage. Cerium and iron show slightly different patterns, which might be caused by the different form of the additives (cerium was dosed as colloidal cerium oxide, iron as organic compound). Additionally iron is a ubiquitous element which might originate from other sources (e.g. abrasion).

The cerium content of the no-additive reference fuel sample RO was close to the detection limit. Significant quantities of cerium were detected for the samples CO and $\mathrm{HCO}$ from the additive-containing fuel sampled without particle trap. The samples $\mathrm{CF}$ and $\mathrm{HCF}$, taken from cleaned gas after the particle trap, only contained ex, tremely low cerium concentrations. The results for iron as a ubiquitous element were not as definite as for cerium. Iron is present in high concentrations throughout the whole technical system. Under the given test conditions the iron originating from the additive could not be clearly distinguished from iron of other sources such as engine abrasion, fuel, test facility, sampling unit, ambient air, et cetera. A mass balance was deduced by comparing the measured analyte content with the total mass of additive content. Therefore the metal masses on the ELPI foils were extrapolated for the total emissions, based on the dilution ratio during sampling. Tables 7 and 8 give the calculated mass balances of iron and cerium. Table 9 shows the aerosol masses determined during sampling, which indicate a high filtration efficiency for particles. According to the mass balance for cerium no significant penetration rate was observed.

The interpretation of the iron data was more difficult. The mass balance for iron gives no clear results, which is probably caused by too many potential contamination sources adulterating the samples. This is also indicated by a negative filtration rate, with emissions sampled without a trap showing a lower iron content than those sampled with a trap. Also for the background level RO, relatively high iron values were detected which must originate from somewhere in the entire system. The results showed clearly that iron is less useful in suitability investigations or risk assessment with particle traps than cerium. A more useful test for iron would require that the additive iron could be clearly distinguished from iron originating from other sources. The use of a radiotracer-doped additive or of an iron additive compound with a significantly different iron isotope ratio than the natural might be imagined. for this task.

It was noticeable that an unexpectedly. large amount of additive was retained in the system. Previous investigations had shown that additives were deposited in the engine and the exhaust system. Additionally, the release of cerium from the engine during the conditioning phase was observed during other tests. These observations were explained by memory effects from earlier use of the engine with additive-containing fuel.
Table 9 Aerosol masses of the impactor stages in $\mathrm{mg}$.

\begin{tabular}{llllllll}
\hline $\begin{array}{l}\text { D 50\% } \\
(\mu \mathrm{m})\end{array}$ & Stage & RO & CO & HCO $\cdots$ & RO & CO & HCO \\
\hline 0.03 & 1 & 0.001 & 0.001 & 0.0008 & 0.0011 & 0.001 & 0.0013 \\
0.06 & 2 & 0.018 & 0.0125 & 0.0139 & 0.0191 & 0.0186 & 0.0201 \\
0.108 & 3 & 0.0634 & 0.049 & 0.058 & 0.089 & 0.082 & 0.084 \\
0.17 & 4 & 0.13 & 0.09 & 0.09 & 0.15 & 0.15 & 0.15 \\
0.26 & 5 & 0.095 & 0.057 & 0.066 & 0.114 & 0.096 & 0.112 \\
0.4 & 6 & 0.25 & 0.13 & 0.17 & 0.33 & 0.26 & 0.28 \\
0.65 & 7 & 0.99 & 0.42 & 0.76 & 1.39 & 0.74 & 1.07 \\
1 & 8 & 2.2 & 1.35 & 2.2 & 3.22 & 2.29 & 2.75 \\
1.6 & 9 & 5.61 & 3.17 & 4.9 & 7.22 & 5.14 & 5.82 \\
2.5 & 10 & 18.7 & 10.6 & 16.3 & 25.2 & 15.6 & 18.5 \\
4.4 & 11 & 70 & 34.6 & 54.2 & 91.8 & 55.9 & 67.2 \\
6.8 & 12 & 331.7 & 142.4 & 243.5 & 420 & 247.3 & 293.5 \\
10 & 13 & & & & & & \\
\hline
\end{tabular}


Presumably, saturation is expected after a "deposition conditioning phase" and the additive amount reaching the particle trap might increase. Therefore an increase in test duration or a pre-driven conditioning phase might increase the amount which can be found in stage $\mathrm{CO}$.

\section{Outlook}

Further investigations should give information on where additive deposits might occur and if an initial deposition phenomenon does exist. Possible deposition locations might be the tank, the engine itself, the exhaust system, or the test facility with the partial dilution tunnel and tubes. Additionally a further investigation of the long-term stability of additive-fuel mixtures is necessary to guarantee stable solutions for general use. A clarification of the influence of additive type, fuel composition (e.g. the $S$ content) etc. on the mixture stability is also needed. Whether lubricants have any effect on particle-trap efficiency is also still unknown. A study of the emissions under distinct operating conditions like the accumulation and regeneration phases is planned for the near future. Outstanding is also the investigation of the long-term behaviour of particle traps as well as the influence of ageing on penetration and soot retention. Finally, different particle trap concepts like additive/particle traps or special metalcoated particle trap systems, which can be operated without additives, should be compared.

\section{Conclusion}

It was clearly shown for cerium that the soot retention of the investigated particle trap was relatively high. According to the demand that appropriate particle traps should not generate significant secondary emissions, the additive release for the additive/particle trap combination described was relatively low for cerium. The interpretation of the iron results was difficult due to too many potential iron sources. It was surprising that only about $10 \%$ of the additive reached the particle trap, which might be caused by initial deposition. Differences in the load and regeneration phases and a possible saturation effect of the additive deposition have to be investigated in further studies.

Acknowledgements We would like to thank A. Mayer (TTM Mayer), N. Heeb (EMPA), T. Mosimann (Matter Eng.), Prof. J. Czerwinski with his group (FH Biel) and SAEFL (BUWAL) for co-operation in VERT projects and for optimisation and sampling in this study.. D. Bleiner is sincerely acknowledged for his valuable help with the manuscript. Last but not least we are very grateful to the Plașma Winter Conference 2003 organising committee.

\section{References}

1. Takizawa H, Abe S, Ohtoshi T, Kawasaki S, Takami K, Desaki M, Sugawara I, Hashimoto S, Azuma A, Nakahara K, Kudoh S (2000) Clin Exp Immunol 120(2):356-362
2. Steerenberg PA, Zonnenberg JA, Dormans JA (1998) Exp Lung Res 24(1): 5-100

3. Davis RJ, Bayram H, Abdelaziz MM, Sapsford RJ, Czarlewski W, Bousquet J (1998) Am J Respir Crit Care Med 157:A743

4. Minami M, Endo T, Hamaue N (1999) Res Commun Mol Pathol Pharmacol 105(1-2):67-76

5. Brunekreef B; Janssen NA, De Hartog J, Harssema H, Knape M, Van Vliet P (1997) Epidemiology 8:298-303

6. SUVA Information zur einführung des partikelfilter-obligatoriums für dieselmotorbetriebene fahrzeuge und masschinen im untertagebau, Luzern, 30 April 2001 http://www.suva.ch/de/ info partikelfilterobligatorium.pdf

7. TRGS 554 Technische Regeln für Gefahrstoffe - Dieselmotorenemissionen (DME), March 2001 http://www.umwelt-online.de/recht

8. VERT Verminderung der Emissionen von Real-Dieselmotoren im Tunnelbau, Abschlussbericht 1 Jan 1994-29 Mar 2000 http:// www.akpf.org/pub/vert_sum_de.pdf

9. SAEFL (2000) Particulate traps for heavy-duty vehicles. Environmental Documentation No. 130, Berne

10. VERT-FLTERLISTE Geprüfte und erprobte partikelfilter-systeme für die nachrüstung von dieselmotoren; Version 17. July 2002 http://www.umwelt-schweiz.ch/buwal/de/fachgebiete/fg_ luft/vorschriften/industrie_gewerbe/filter/

11. Heeb N et al (1998) Influence of particulate trap systems on the composition of diesel engine exhaust gas emissions. EMPA Research Report No.167985.

12 . Heeb $\mathrm{N}$ et al (1998) Influence of particulate trap systems on the composition of diesel engine exhaust gas emissions (Part II). EMPA Research Report No.172847

13. Nölte J (2003) ICP emission spectrometry - a practical guide. Wiley, Weinheim

14. Fassel VA, Peterson CA, Abercrombie FN, Knieseley RN (1976) Anal Chem 48:516-519

15. Merryfield RN, LLoyd RC (1979) Anal Chem 51:1965-1968

16. Boumans PWJM, Lux-Ṣteiner MC (1982) Spectrochim Acta 37B:97-126

17. McElroy F, Mennito A, Debrah E, Thomas R (1994) Spectroscopy $13(2): 42-53$

18. Borszeki J, Bartha L (1991) Acta Chim Hung 28(4-5):633-637

19. Fabec JL, Ruschak ML (1985) Anal Chem 57:1853-1863.

20. Brockaert JAC, Keis F, Laqua K (1981) Talanta 28:745-752

21. Hauptmann G, Bernhard U, Engelke K, Fuchs A, Hönel E, Polzer G (1988) Schınierungstechnik 19:19-21

22. Kuokkanen T, Permämäki P, Völimäki I, Pönklömäki H (2001) Int J Environ Anal Chem 81:89-100

23. Brennier IB, Zander AT (2000) Spectrochim Acta B 55:1195-1240

24. Krengel-Rothensee K, Richter U, Heitland P (1999) J Anal At Spectrom 14:699-702

25. Andreau C, Fredeen KT, Thomsen M, Yates DA (1995)At Spectrose 16:79-81

26. Hassler S, Noelte J, Ulrich A (2003) Alternate solvents for the direct analysis of organic samples by ICP-OES. Poster at the European winter conference on plasma spectrochemistry, Garmisch Partenkirchen, 2003

27. Kingston HM, Jassie LB (eds) (1988) Introduction to microwave sample preparation - theory and practice. ACS Professional Reference Book, American Chemical Society, Washington

28. Babu SP (ed) (1975) Trace elements in fuel. American Chemical Society, Washington

29. Sulcek Z, Povondra P (1989) Methods of decomposition in inorganic analysis. CRC, Boca Ŕaton

30. Kägler SH (ed) (1987) Neue mineralölanalyse, band 1: spektroskopie. Hüthig, Heidelberg

31. Ulrich A, Wichser A (2002) Metal analysis of diesel vehicle emissions. In: Proceedings of 6th conference on nanoparticle measurement, August 2002

32. Mayer A, Ulrich A, Czerwinski J, Matter U, Wyser M (2003) . SAE paper 2003-01-0287 
33. Keskinen J, Pietarinen K, Lehtimäki M (1992) J Aerosol Sci -38. Figler B, Sahile W, Krantz S, Ulfvarson U (1996) Sci Total Env 23:353-360

193(2):77-83

34. Marjamäki M, Keskinen J, Chen D, Pui DYH (2000) J Aerosol Sci 31:249-261

35. van Gulijk C, Schouten JM, Marijnissen JCM, Makkee M, Moulijn JA (2001) J Aerosol Sci 32(9):1117-1130

36. Harris SJ, Maricq MM (2001) J Aerosol Sci 32:749-764

37. Bérubé KA, Jones TP, Williamson BJ, Winters C, Morgan AJ, Richards RJ (1999) Atm Env.33(10):1599-1614

39. Matter U, Siegmann K (1997) The influence of particle filter and fuel additives on turbo diesel engine exhaust. J Aerosol Sci 28(1):551-552

40. Skillas G, Qian Z, Baltensberger U, Matter U, Burtscher H (2000) The influence of additives on the size distribution and composition of particles produced by diesel engines. Combust Sci Tech 154:259-273 